\title{
Distinct Populations of Neurons Activated by Heroin and Cocaine in the Striatum as Assessed by catFISH
}

\author{
Philip Vassilev, ${ }^{1}{ }^{\circledR}$ Riccardo Avvisati, ${ }^{1}{ }^{\circledR}$ Eisuke Koya, ${ }^{1}$ and ${ }^{\circledR}$ Aldo Badiani ${ }^{1,2}$
}

https://doi.org/10.1523/ENEURO.0394-19.2019

${ }^{1}$ Sussex Addiction Research and Intervention Centre (SARIC), School of Psychology, University of Sussex, Brighton BN1 9RH, United Kingdom and ${ }^{2}$ Department of Physiology and Pharmacology, Sapienza University of Rome, 00185 Rome, Italy

\begin{abstract}
Despite the still prevailing notion of a shared substrate of action for all addictive drugs, there is evidence suggesting that opioid and psychostimulant drugs differ substantially in terms of their neurobiological and behavioral effects. These differences may reflect separate neural circuits engaged by the two drugs. Here we used the catFISH (cellular compartment analysis of temporal activity by fluorescence in situ hybridization) technique to investigate the degree of overlap between neurons engaged by heroin versus cocaine in adult male Sprague Dawley rats. The catFISH technique is a within-subject procedure that takes advantage of the different transcriptional time course of the immediate-early genes homer $1 a$ and arc to determine to what extent two stimuli separated by an interval of 25 min engage the same neuronal population. We found that throughout the striatal complex the neuronal populations activated by noncontingent intravenous injections of cocaine $(800 \mu \mathrm{g} / \mathrm{kg})$ and heroin (100 and $200 \mu \mathrm{g} / \mathrm{kg}$ ), administered at an interval of $25 \mathrm{~min}$ from each other, overlapped to a much lesser extent than in the case of two injections of cocaine $(800 \mu \mathrm{g} / \mathrm{kg})$, also $25 \mathrm{~min}$ apart. The greatest reduction in overlap between populations activated by cocaine and heroin was in the dorsomedial and dorsolateral striatum ( $\sim 30 \%$ and $\sim 22 \%$, respectively, of the overlap observed for the sequence cocaine-cocaine). Our results point toward a significant separation between neuronal populations activated by heroin and cocaine in the striatal complex. We propose that our findings are a proof of concept that these two drugs are encoded differently in a brain area believed to be a common neurobiological substrate to drug abuse.
\end{abstract}

Key words: addiction; neuroplasticity; nucleus accumbens; opioid; psychostimulant; striatal complex

\section{Significance Statement}

Despite significant advances in the substance use disorders field, effective prevention and treatment strategies are scarce and still under active development. Here we add to growing evidence indicating major differences in the neurobiological effects of opioid versus psychostimulant drugs, which is at odds with the still prevailing notion of a shared substrate of action for all addictive drugs. This suggests that, to be effective, the development of prevention and treatment strategies should not look for a "silver bullet" solution to all drug addictions. Instead, they should be tailored to the specific drug preference of pathologic users.

\section{Introduction}

Virtually all current theories of drug abuse posit that the addictive properties of drugs depend on common neuro-

Received September 30, 2019; accepted December 19, 2019; First published January 14, 2020.

The authors declare no competing financial interests. biological processes, including hyper-reactivity of motivational systems (Wolf, 2010; Berridge and Robinson, 2016), impaired impulse control (Jentsch and Taylor, 1999), and 
aberrant learning (Everitt and Robbins, 2005). Regardless of the core process on which each theory focuses, the biological substrate of said processes involves the mesotelencephalic dopamine (DA) system projecting from ventral tegmental area (VTA) and substantia nigra to the striatal complex, including caudate and nucleus accumbens (NAcC), and to the prefrontal cortex (PFC). Indeed, it is commonly assumed that all substances of abuse increase dopamine levels in the terminal regions of the dopaminergic system (Di Chiara and Imperato, 1988; Robinson and Berridge, 1993; Wise, 1996; Nestler, 2001, 2004; Hyman et al., 2006; Koob and Volkow, 2010; Berridge, 2012; Covey et al., 2014; Keiflin and Janak, 2015; Volkow and Morales, 2015; Berridge and Robinson, 2016; Keramati et al., 2017; Volkow et al., 2017) albeit via different mechanisms of action. Psychostimulant drugs, such as cocaine and amphetamines, produce dopamine overflow by binding the dopamine transporter (for review, see Kuczenski et al., 1982; Johanson and Fischman, 1989). Opioid agonists, such as heroin and morphine, are thought to increase dopamine concentrations indirectly by binding $\mu$-opioid receptors located on inhibitory interneurons in the VTA; hence, disinhibiting dopaminergic neurons (Gysling and Wang, 1983; Matthews and German, 1984; Johnson and North, 1992). Yet, the magnitude of drug-induced dopamine overflow differs enormously from one drug to another, even within the same pharmacological class. For example, some opioids produce dramatic increases in dopamine, whereas others have very little effect (Gottås et al., 2014; Vander Weele et al., 2014). Furthermore, electrophysiological experiments have shown that neurons in the striatum respond in a very different manner to heroin versus cocaine self-administration (Chang et al., 1998; Wei et al., 2018), suggesting that the effects of the two drugs are encoded differently in this brain area.

The aim of the two experiments reported here was to further explore this hypothesis using the catFISH (cellular compartment analysis of temporal activity by fluorescence in situ hybridization) technique, which is a withinsubject technique that takes advantage of the different transcriptional time course of the immediate-early genes (IEGs) homer 1a (h1a) and arc to detect the activation of partly distinct neuronal populations in response to two temporally distinct stimuli (Fig. 1; Guzowski et al., 1999; Vazdarjanova et al., 2002; Vazdarjanova and Guzowski, 2004). To date, a few studies have looked at the effects of cocaine on arc ( Caffino et al., 2011) or homer 1a expression (Unal et al., 2009), whereas there is no information on the effects of heroin administration on the expression of

The study was supported by funding from the University of Sussex (Strategic Development Funds) to A.B.

Acknowledgments: We thank Dr. Sarah King and Dr. Hans Crombag for their expert advice.

Correspondence should be addressed to Aldo Badiani at Aldo.badiani@gmail.com.

https://doi.org/10.1523/ENEURO.0394-19.2019

Copyright () 2020 Vassilev et al.

This is an open-access article distributed under the terms of the Creative Commons Attribution 4.0 International license, which permits unrestricted use, distribution and reproduction in any medium provided that the original work is properly attributed.
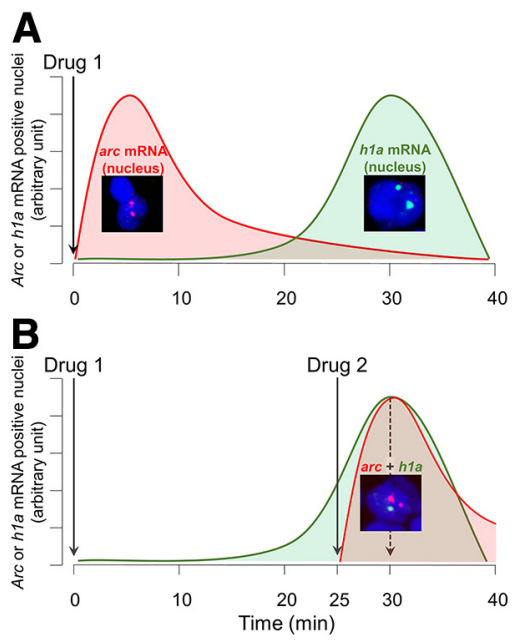

Figure 1. The catFISH paradigm. Working hypothesis based on the review by Guzowski et al. (2005): the expression of mRNA encoding for $h 1 a$ and arc should be detectable at different time points after drug administration. $\boldsymbol{A}$, arc mRNA expression in the nucleus should peak at $\sim 5 \mathrm{~min}$ after drug administration, whereas h1a mRNA should peak at $\sim 30 \mathrm{~min}$. $\boldsymbol{B}$, Overlap in the expression of Drug 1-induced h1a mRNA and Drug 2-induced arc mRNA should be observed at time $30 \mathrm{~min}$ ( $25 \mathrm{~min}$ after Drug 1 and 5 min after Drug 2).

these two IEGs. As in the case of the IEG c-fos, which is known to be transcribed across the striatum in response to heroin and cocaine administration (Harlan and Garcia, 1998; Paolone et al., 2007; Celentano et al., 2009), both arc and homer 1a are activated by the transcription factor CREB; that is, they are transcribed following the activation of the ERK/MAPK pathway, elevated CAMP activity, or calcium influx to the cell (Impey et al., 1998; Sato et al., 2001; Kawashima et al., 2014). Considering these shared mechanisms of expression, we expected that arc and homer 1a would be suitable markers of neuronal activity produced by drug administration. We predicted that intravenous injections of heroin and cocaine will produce a rapid and transient IEG transcription in the striatum. Indeed, we found that intravenous administration of low doses (i.e., those typically used in self-administration experiments) of heroin and cocaine produce temporally distinct increases in the expression of $h 1 a$ and/or arc suggesting that both drugs induce neuronal activity across the striatum. In a second experiment, we used the catFISH technique to establish to what extent this activity occurs in overlapping versus drugspecific neuronal populations. Based on electrophysiological evidence suggesting distinct neuronal activity produced by heroin versus cocaine (Chang et al., 1998), we predicted that the administration of heroin following cocaine would activate nonoverlapping neuronal populations across the striatum.

\section{Materials and Methods}

\section{Subjects}

A total of 66 male Sprague Dawley rats $[n=37$ in experiment (Exp) 1 and $n=29$ in Exp 2] from ENVIGO were tested at a weight of 300-375 g. The rats were housed and tested in a temperature- and humidity- 
controlled room $\left(21 \pm 1{ }^{\circ} \mathrm{C} ; 50 \%\right)$ with a reversed $12 \mathrm{~h}$ light/dark cycle (lights on at 7:00 P.M.). The rats were housed in groups of three or four until surgery and individually thereafter. Food and water were provided ad libitum except during testing sessions. All regulated procedures were conducted in accordance with the UK 1986 Animal Scientific Procedures Act (ASPA) and received approval from the relevant Animal Welfare and Ethics Review Board. After their arrival in the animal facilities, the rats were given a period of at least $7 \mathrm{~d}$ before undergoing experimental procedures.

\section{Drugs}

Anesthesia was induced with $110 \mathrm{mg} / \mathrm{kg}$ ketamine (Anesketin, Dechra) and $2 \mathrm{mg} / \mathrm{kg}$ xylazine (Rompun, Bayer HealthCare). Cocaine and heroin hydrochloride (Johnson Matthey-MacFarlan Smith) were dissolved in sterile saline and infused intravenously at the doses specified in the next paragraphs. Each infusion consisted of a volume of $40 \mu \mathrm{l}$ of the appropriate drug solution delivered over $4 \mathrm{~s}$. Saline-treated rats received equivalent volumes of saline.

\section{Intravenous catheter surgery}

The surgical procedures were similar to those recently described by Avvisati et al. (2019). Briefly, after anesthesia, an $11 \mathrm{~cm}$ silicone catheter $(0.37 \mathrm{~mm}$ inner diameter, $0.94 \mathrm{~mm}$ outer diameter), sheathed at $3.4 \mathrm{~cm}$ from its proximal end by a silicone bead, was implanted in the right jugular vein, externalized at the nape of the neck, and attached to a cannula secured to the top of the skull with dental cement. Following surgery, rats were allowed to recover for at least $7 \mathrm{~d}$. Catheter patency was maintained by flushing the catheters daily with $0.1 \mathrm{ml}$ saline.

\section{Catheter patency test}

At the appropriate time (see next sections), the rats were killed via an intravenous infusion of pentobarbital (120 mg/kg in $200 \mu$ l of saline) through the catheter. This also served as a catheter patency test: the rats that did not become ataxic and die within $5 \mathrm{~s}$ would be excluded from the data analysis. All catheters were found to be patent.

\section{Drug administration procedures \\ Experiment 1}

After recovery, the rats received, while briefly restrained, an intravenous infusion of either $400 \mu \mathrm{g} / \mathrm{kg}$ cocaine $(n=18)$ or $50 \mu \mathrm{g} / \mathrm{kg}$ heroin $(n=19)$ in their home cage. These doses were selected based on the findings of previous selfadministration experiments (Caprioli et al., 2007b, 2008). The rats received the lethal pentobarbital injection and were then decapitated at different time points after the cocaine or heroin infusion, as follows: 0 min $n=3$ for both the cocaine and heroin groups), $8 \mathrm{~min}$ ( $n=3$ for both the cocaine and heroin groups), 16 min ( $n=4$ for both the cocaine and heroin groups), 25 min ( $n=4$ for both the cocaine and heroin groups), and $35 \min$ ( $n=4$ and $n=5$ for the cocaine and heroin groups, respectively).

\section{Experiment 2}

After recovery, the rats were moved to testing chambers used for self-administration experiments (PRS Italia;
Avvisati et al., 2019). To reduce the potentially confounding effects of environmental novelty on drug-induced IEG expression (Uslaner et al., 2001; Paolone et al., 2007), we let the rats habituate to these chambers for $18 \mathrm{~h}$ before tethering them to the infusion lines. Food and water were available ad libitum during this habituation period and were removed immediately before tethering. The use of self-administration chambers allowed us to deliver drug infusions remotely via a computer-controlled infusion pump. The infusion pumps were programmed to start automatically, in the absence of the experimenter, $1 \mathrm{~h}$ after tethering. In this way, we avoided the confounding effects usually associated with signaled drug administration (Crombag et al., 1996) and/or handling. All rats received two intravenous infusions, $25 \mathrm{~min}$ apart, of the following: saline-saline $(n=4)$, cocaine $800 \mu \mathrm{g} / \mathrm{kg}$-saline $(n=6)$, cocaine $800 \mu \mathrm{g} / \mathrm{kg}$-cocaine $800 \mu \mathrm{g} / \mathrm{kg}(n=6)$, cocaine $800 \mu \mathrm{g} / \mathrm{kg}$-heroin $100 \mu \mathrm{g} / \mathrm{kg}(n=6)$, or cocaine $800 \mu \mathrm{g} / \mathrm{kg}$-heroin $200 \mu \mathrm{g} / \mathrm{kg}(n=7)$. To administer two separate injections through the same catheter, the infusion lines were backfilled with the appropriate drug solutions, separated by a tiny air bubble, just before tethering of the rats. The rationale for using higher doses of cocaine and heroin in Exp 2 was to boost the magnitude of IEG expression. These doses were still within the range of those used in self-administration experiments (Zito et al., 1985; Dai et al., 1989; Roberts et al., 1989; Pettit and Justice, 1991; Shaham and Stewart, 1994; Wise et al., 1995; Mantsch et al., 2001; Wee et al., 2007; Mandt et al., 2012).

Five minutes after the second infusion, the rats were given $120 \mathrm{mg} / \mathrm{kg}$ pentobarbital, i.v., and, after decapitation, their brains were snap frozen in isopentane at $-50^{\circ} \mathrm{C}$

\section{Brain slicing}

The brains were excised and snap frozen in $400 \mathrm{ml}$ of isopentane cooled to $-50^{\circ} \mathrm{C}$ and later sectioned on a cryostat at 16 or $20 \mu \mathrm{m}$ thickness. In Exp 1, sectioning started from the tip of the olfactory bulbs and brain sections were removed until the Sylvian fissure no longer reached the midline $(+3.70 \mathrm{~mm}$ from bregma). At this point, either 100 or 80 sections were removed (when sectioning at 16 and $20 \mu \mathrm{m}$, respectively) to reach +2.00 $\mathrm{mm}$ from bregma at which point the sections contained anterior dorsal striatum (DS) and NAcc core (Fig. 2A). Two coronal sections per rat (16 or $20 \mu \mathrm{m}$ thick) were obtained at this point. An identical procedure was used in $\operatorname{Exp} 2$ to collect two coronal sections containing NAcc core and shell, dorsomedial striatum (DMS), and dorsolateral striatum (DLS) at $+1.70 \mathrm{~mm}$ from bregma (Fig. $3 A$ ).

\section{In situ hybridization}

Immediately after cutting, the brain tissue sections were mounted on Superfrost Plus slides. On the first day of staining, the slides were incubated in $10 \%$ neutral buffered formalin (catalog \#HT501128-4L, Sigma-Aldrich) for $20 \mathrm{~min}$ at $4^{\circ} \mathrm{C}$, followed by $2 \times 1 \mathrm{~min}$ washes in $1 \times$ PBS, and then serial dehydration in ascending concentrations of ethanol (5 min incubation in 50\%, 70\%, and $2 \times 100 \%$ ). Following this, the tissue was stored in $100 \%$ ethanol 
A

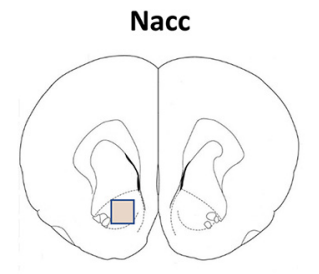

DS

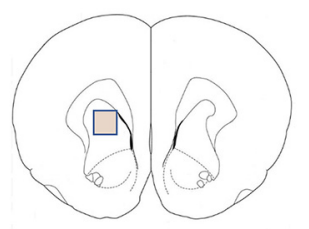

B
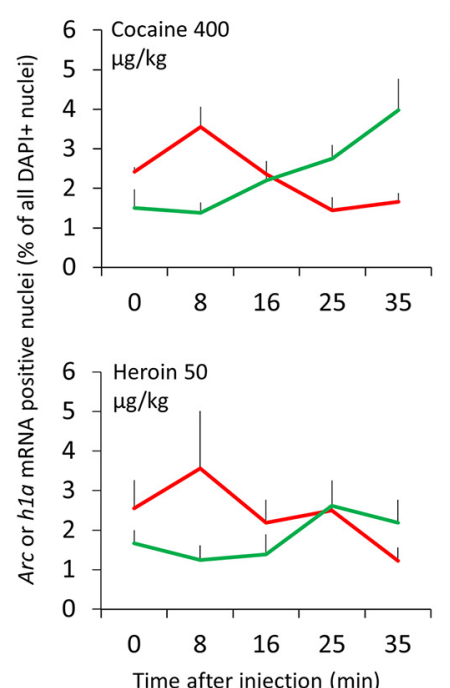

h1a
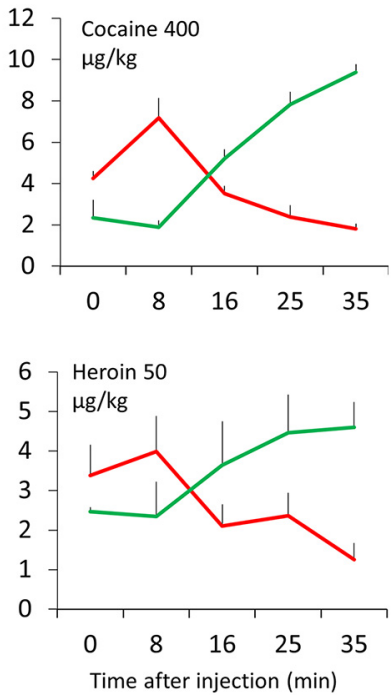

Figure 2. Effect of single drug injections on IEG expression. Time course of arc mRNA and h1a mRNA expression in experiment 1. $\boldsymbol{A}$, Regions of interest (plate from Paxinos and Watson, 1986). B, Average number of arc- or $h 1 a^{+}$cell nuclei as a function of brain area and administered drug (expressed as a percentage of all $\mathrm{DAPI}^{+}$nuclei). The brains were excised at different time points after drug administration, as follows: $0 \min (n=3$ for both the cocaine and heroin groups), $8 \mathrm{~min}$ ( $n=3$ for both the cocaine and heroin groups), $16 \mathrm{~min}$ ( $n=4$ for both the cocaine and heroin groups), $25 \min (n=4$ for both the cocaine and heroin groups), and $35 \min (n=4$ and $n=5$ for the cocaine and heroin groups, respectively).

overnight. On day 2, the tissue was air dried and then incubated with protease for $20 \mathrm{~min}$, followed by $2 \times 1 \mathrm{~min}$ washes in distilled $\mathrm{H}_{2} \mathrm{O}$. Protease, probe, and amplifier solutions were supplied by Advanced Cell Diagnostics (ACDbio) as part of a commercially available RNAscope Kit (ACDbio). Arc and h1a hybridization probes (catalog \#317071-C2 and \#433261, respectively, ACDbio) were hybridized to fresh frozen brain coronal sections sliced on a Leica CM1900 cryostat. The signal was amplified with an RNAscope Multiplex Fluorescent Reagent Kit (catalog \#320850, ACDbio). The arc probe targeted the region spanning 1519-2621 bp of the arc gene mRNA (accession No. NM_019361.1). The h1a probe targeted the 3' untranslated region of the h1a gene mRNA, spanning 5001-5625 bp (accession \#U92079.1).

The arc and $h 1 a$ probes were applied (50 $\mu \mathrm{l} / \mathrm{section})$, and the sections were incubated for $2 \mathrm{~h}$ at $40^{\circ} \mathrm{C}$ in a humidity-controlled oven. After incubation with the probes, the signal was amplified at four separate stages with 15 , 30,15 , and 30 min of incubation in between (respectively) at $40^{\circ} \mathrm{C}$ in the hybridization oven. The probe and amplifier

A

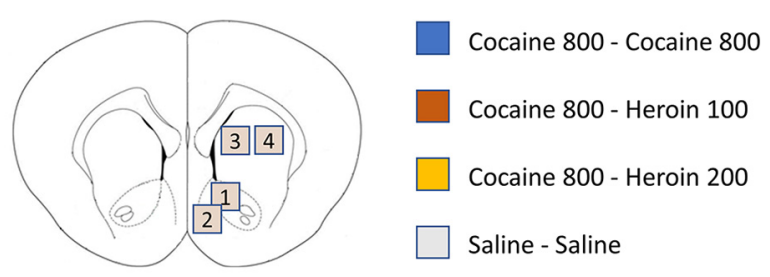

B



Figure 3. Overlap in the neuronal populations engaged by heroin and cocaine. Coexpression of arc and h1a mRNAs in experiment 2. A, Regions of interest (plate from Paxinos and Watson, 1986). $\boldsymbol{B}$, Overlap expressed as the percentage of overlap in the cocaine-cocaine condition as a function of brain area and drugs administered, $25 \mathrm{~min}$ apart, in $\operatorname{Exp} 2$ : saline-saline $(n=4)$, cocaine $(800 \mu \mathrm{g} / \mathrm{kg})$-saline $(n=6)$, cocaine $(800 \mu \mathrm{g} / \mathrm{kg})$-cocaine $(800 \mu \mathrm{g} / \mathrm{kg} ; n=6)$, cocaine $(800 \mu \mathrm{g} / \mathrm{kg})$-heroin $100 \mu \mathrm{g} / \mathrm{kg}(n=$ $6)$, and cocaine $(800 \mu \mathrm{g} / \mathrm{kg})$-heroin $200 \mu \mathrm{g} / \mathrm{kg}(n=7)$.

solutions were applied to the sections with the help of a hydrophobic pen barrier. There were $2 \times 2$ min washes in wash buffer after each incubation (including after probe hybridization). Finally, sections were coverslipped and counterstained with DAPI mounting medium (catalog \#H1500 , Vector Laboratories) and left at $4^{\circ} \mathrm{C}$ overnight.

\section{Image acquisition and analysis}

Fluorescent signal was detected using a Zeiss Axioskop 2 Plus epifluorescent microscope, and images were acquired using AxioVision software (Zeiss).

Grayscale images were taken from both hemispheres of two adjacent sections for each rat at $20 \times$ magnification. This yielded four images per brain area for each rat. Final counts of DAPI-, arc-, and $h 1 a^{+}$nuclei were averaged from these four images. The resulting images represented a region of interest of $700 \times 550 \mu \mathrm{m}$. These images were analyzed using the RIO Montpelier extension of the ImageJ software (Baecker and Travo, 2006). Grayscale images were analyzed separately for each channel-DAPI, Alexa Fluor 488 (h1a) and Cy3 (arc)-as follows. First, each DAPI image was analyzed by applying a Gaussian blur filter (sigma $=2$ ), then a "rolling ball" background subtraction algorithm (ball radius $=20$ ), followed by the application of the default automatic global thresholding algorithm. This yielded a binary image, which was then used to count objects selected on the basis of their size and circularity using the "analyze particles" function of ImageJ. The size criterion was set to $0.0045-0.045$ 
Table 1: Mean (SE) number of arc- and h1a-stained cell nuclei as a function of brain area and drug administered in Exp 1

\begin{tabular}{|c|c|c|c|c|c|c|c|c|}
\hline & \multicolumn{4}{|c|}{ NAcc } & \multicolumn{4}{|c|}{ DS } \\
\hline & \multicolumn{2}{|c|}{ Cocaine $(400 \mu \mathrm{g} / \mathrm{kg})$} & \multicolumn{2}{|c|}{ Heroin $(50 \mu \mathrm{g} / \mathrm{kg})$} & \multicolumn{2}{|c|}{ Cocaine $(400 \mu \mathrm{g} / \mathrm{kg})$} & \multicolumn{2}{|c|}{ Heroin $(50 \mu \mathrm{g} / \mathrm{kg})$} \\
\hline & Arc & $\mathrm{H} 1 \mathrm{a}$ & Arc & $\mathrm{H} 1 \mathrm{a}$ & Arc & $\mathrm{H} 1 \mathrm{a}$ & Arc & $\mathrm{H} 1 \mathrm{a}$ \\
\hline $\mathrm{m}$ & $9.50(1$ & $12.50(4.44)$ & $18.42(6.86)$ & 11.33 & 010 & 16.42 & $17(6$ & 14. \\
\hline $\mathrm{m}$ & 5.50 & $9.75(2$. & $26.92(1$ & & & & & 14 \\
\hline $16 r$ & 16. & 14 & & & & & & \\
\hline $25 \mathrm{~min}$ & $9.94(2.78)$ & $17.81(0.82)$ & $18.19(3.95)$ & $18.69(4.29)$ & 15.00 & $48.88(5.99)$ & $16.44(3.76)$ & $31.75(7.3)$ \\
\hline $35 \mathrm{~min}$ & $11.00(1.67)$ & 26.25 (5.13) & $8.00(2.22)$ & $14.6(4.26)$ & $11.25(1.44)$ & $58.50(1.52)$ & $7.50(2.2)$ & $28.35(4.58)$ \\
\hline
\end{tabular}

The brains were excised at different time points after drug administration: 0 min ( $n=3$ for both the cocaine and heroin groups), 8 min $(n=3$ for both the cocaine and heroin groups), $16 \min (n=4$ for both the cocaine and heroin groups), $25 \min (n=4$ for both the cocaine and heroin groups), and 35 min ( $n=4$ and $n=5$ for the cocaine and heroin groups, respectively)

square inches, and the circularity-to 0.7-1.00. This analysis resulted in a binary mask image containing only objects fulfilling the aforementioned criteria.

The images from the Alexa Fluor 488 and Cy3 channels were first adjusted for brightness so that the most visible signal was that coming from nuclear staining for arc and h1a. This was defined as any signal representing one or two bright dots close to each other, as opposed to the cytoplasmic signal, which is less bright and more diffused (Guzowski et al., 1999). A global threshold was then applied to the images (default algorithm), and the "analyze particles" function was used again to select only objects of 4-90 square pixels and to create a binary image mask showing only the defined particles.

A Windows 10 Dell OptiPlex 7060 desktop computer ran a MATLAB script to overlay the three binary mask images and count instances where objects defined as DAPI nuclei coincided with objects defined as arc mRNA, h1a mRNA, or both. The MATLAB code will be made available on request. Thus, IEG expression was measured by counting $\mathrm{DAPI}^{+}$cell nuclei also positive for $h 1 \mathrm{a}$, arc, or both.

\section{Statistical analyses}

The data from Exp 1 were analyzed by two-way mixed ANOVAs, with time and IEG as fixed factors. The number of $\mathrm{IEG}^{+}$cell nuclei (as a percentage of all DAPI-stained nuclei) was the dependent variable. The data from Exp 2 were analyzed using a two-way ANOVA, with brain area and treatment group as fixed factors. The outcome variable was overlap (expressed as a percentage of the cocaine-cocaine group). All analyses were conducted in SPSS 25 software (IBM). An $\alpha$ value of $\leq 0.05$ was used for determining statistically significant effects.

\section{Results}

\section{Experiment 1 (time course of Arc and h1a expression following intravenous drug administration)}

Figure $2 B$ shows the amount of arc and $h 1 a^{+}$nuclei in the NAcc core and DMS expressed as a percentage of all $\mathrm{DAPI}^{+}$nuclei and as a function of time elapsed since intravenous injections of cocaine and heroin. Table 1 shows the same data before conversion to a percentage.

\section{Arc and h1a expression in the NAcc core}

Cocaine administration increased both arc and h1a mRNA levels in the NAcc core, but at different time points.
A two-way mixed ANOVA showed nonsignificant main effects of IEG $\left(F_{(1,13)}=0.08, p=0.782, \eta^{2}=0.006\right)$ and time $\left(F_{(4,13)}=1.62, p=0.227, \eta^{2}=0.333\right)$, but a significant time $\times$ IEG interaction $\left(F_{(4,13)}=7.93, p=0.002, \eta^{2}\right.$ $=0.977$ ).

Heroin produced a similar pattern of mRNA expression, but the effect did not reach significance: a two-way mixed ANOVA showed nonsignificant main effects of IEG $\left(F_{(1,14)}\right.$ $\left.=2.32, p=0.150, \eta^{2}=0.142\right)$ and time $\left(F_{(4,14)}=0.72, p\right.$ $\left.=0.596, \eta^{2}=0.17\right)$, and a nonsignificant time $\times$ IEG interaction $\left(F_{(4,14)}=2.15, p=0.129, \eta^{2}=0.38\right)$.

\section{Arc and h1a expression in the DMS}

As in the NAcc core, cocaine treatment increased IEG levels in a time-dependent manner. A two-way mixed ANOVA showed significant main effects of IEG $\left(F_{(1,13)}=\right.$ 18.93, $\left.p=0.001, \eta^{2}=0.593\right)$ and time $\left(F_{(4,13)}=5.36, p=\right.$ $0.009, \eta^{2}=0.623$, and a significant time $\times$ IEG interaction $\left(F_{(4,13)}=44.58, p<0.001, \eta^{2}=0.932\right)$.

Heroin produced a similar effect. A two-way mixed ANOVA showed nonsignificant main effects of IEG $\left(F_{(1,14)}\right.$ $\left.=3.17, p=0.097, \eta^{2}=0.185\right)$ and time $\left(F_{(4,14)}=0.22, p\right.$ $\left.=0.924, \eta^{2}=0.059\right)$, but a significant time $\times$ IEG interaction $\left(F_{(4,14)}=3.58, p=0.033, \eta^{2}=0.506\right)$.

\section{Experiment 2 (overlap in neuronal populations activated by cocaine and heroin)}

Table 2 shows the average number of arc-only, h1aonly, and double-stained cell nuclei as a function of brain area and drugs administered in experiment 2. Figure 4-Figure 7 show representative images from all brain areas analyzed using catFISH.

Figure $3 B$ shows the extent of overlap between neuronal populations activated by cocaine and heroin as a percentage change from the cocaine-cocaine group. Overlap was quantified as the number of nuclei coexpressing arc and $h 1 \mathrm{a}$ expressed as a percentage of all $\mathrm{mRNA}^{+}$nuclei (single and double labeled). In all four brain areas examined, there was a substantial reduction in overlap when cocaine and heroin were administered in succession, relative to the overlap seen when cocaine was administered twice, and regardless of heroin dose (Fig. 3). A two-way mixed ANOVA showed a significant main effect of treatment group $\left(F_{(3,19)}=20.97, p<0.001\right.$, $\left.\eta^{2}=0.768\right)$ and brain area $\left(F_{(3,57)}=3.40, p=0.024, \eta^{2}=\right.$ $0.152)$, but not treatment $\times$ brain area interaction $\left(F_{(9,57)}=\right.$ $\left.0.79, p=0.619, \eta^{2}=0.112\right)$. 
Table 2. Mean (SE) number of h1a-only, arc-only, and double-stained cell nuclei as a function of brain area and drugs administered, $25 \mathrm{~min}$ apart, in $\operatorname{Exp} 2$ : saline-saline $(n=4)$, and cocaine $(800 \mu \mathrm{g} / \mathrm{kg})-\mathrm{saline}(n=6)$, cocaine $(800$ $\mu \mathrm{g} / \mathrm{kg})$-cocaine $(800 \mu \mathrm{g} / \mathrm{kg} ; n=6)$, cocaine $(800 \mu \mathrm{g} / \mathrm{kg})$-heroin $100 \mu \mathrm{g} / \mathrm{kg}(n=6)$, and cocaine $(800 \mu \mathrm{g} / \mathrm{kg})-\mathrm{heroin} 200$ $\mu \mathrm{g} / \mathrm{kg}(n=7)$

\begin{tabular}{|c|c|c|c|c|c|}
\hline & & NAcc core & NAcc shell & DMS & DLS \\
\hline First saline & h1a & $4.94(0.66)$ & $4.44(1.61)$ & $5.98(2.18)$ & $8.5(2.54)$ \\
\hline Double & & $0.13(0.07)$ & $0.38(0.16)$ & $0.13(0.07)$ & $0.13(0.13)$ \\
\hline Second saline & arc & $4.25(0.77)$ & $3.13(0.68)$ & $5.58(1.77)$ & $4.33(0.95)$ \\
\hline Double & & $1.46(0.25)$ & $1.67(0.35)$ & $3.63(0.43)$ & $4.46(1.49)$ \\
\hline First cocaine $(800 \mu \mathrm{g} / \mathrm{kg})$ & h1a & $20.54(5.45)$ & $11.00(2.87)$ & $42.17(8.65)$ & $49.71(7.5)$ \\
\hline First cocaine $(800 \mu \mathrm{g} / \mathrm{kg})$ & h1a & $20.33(3.72)$ & $8.04(2.36)$ & $58.67(16.42)$ & $66.04(11.36)$ \\
\hline Second heroin $(100 \mu \mathrm{g} / \mathrm{kg})$ & arc & $23.29(9.55)$ & $18.92(9.13)$ & $3.63(0.70)$ & $3.04(1.06)$ \\
\hline Double & & $5.00(2.07)$ & $2.46(0.87)$ & $4.17(1.19)$ & $3.63(0.96)$ \\
\hline First cocaine $(800 \mu \mathrm{g} / \mathrm{kg})$ & h1a & $18.96(4.33)$ & $7.57(1.75)$ & $50.68(7.34)$ & $56.46(7.64)$ \\
\hline Seconds heroin $(200 \mu \mathrm{g} / \mathrm{kg})$ & $\operatorname{arc}$ & $12.11(1.53)$ & $12.61(2.91)$ & $5.17(0.74)$ & $4.32(1.16)$ \\
\hline Double & & $3.14(0.59)$ & $1.75(0.49)$ & $3.11(0.46)$ & $3.93(0.93)$ \\
\hline
\end{tabular}
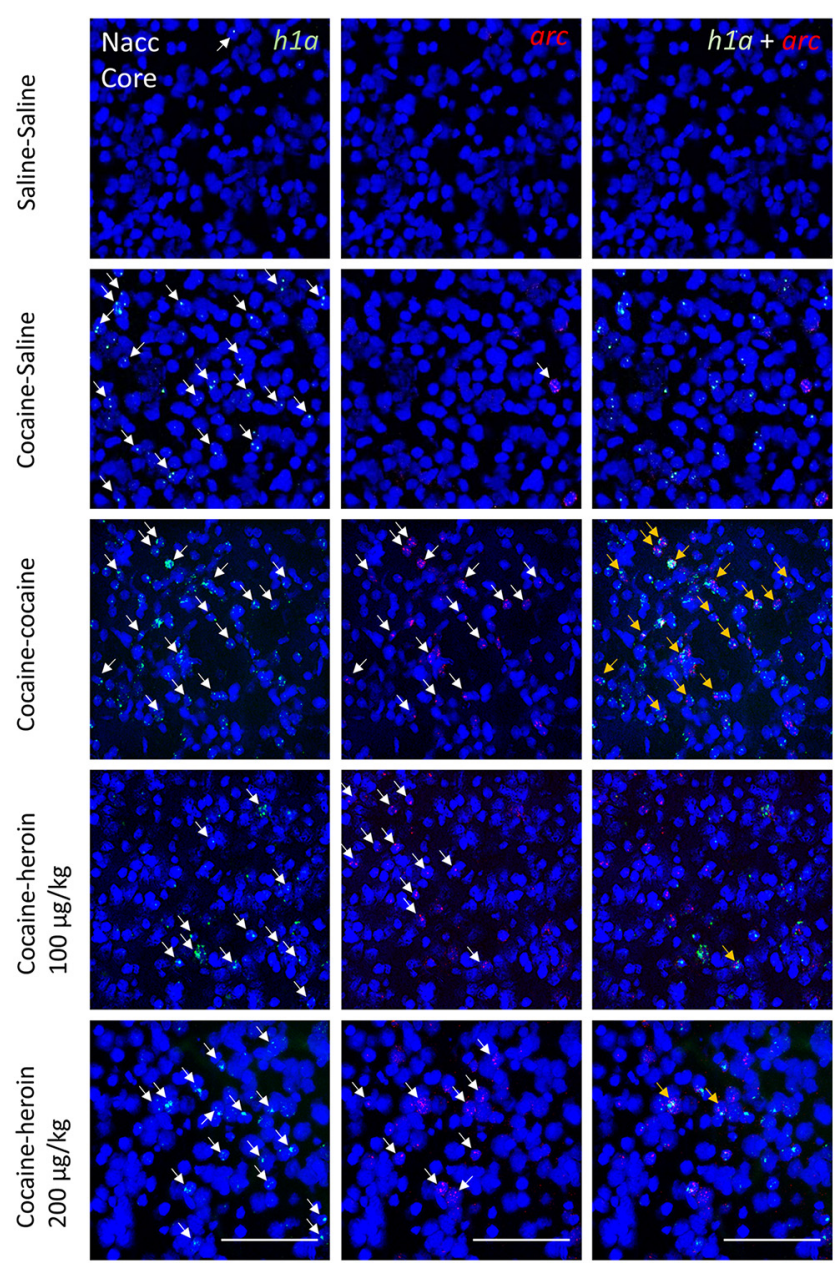

Figure 4. Representative microscope images taken from the NAcc core. DAPI-stained cell nuclei (blue) coexpress only h1a (green), only arc (red), or both. The columns show green and red channels separately and then merged. Taken from Nacc core. Scale bars, $0.1 \mathrm{~mm}$. Arrows point to $\mathrm{mRNA}^{+}$nuclei.
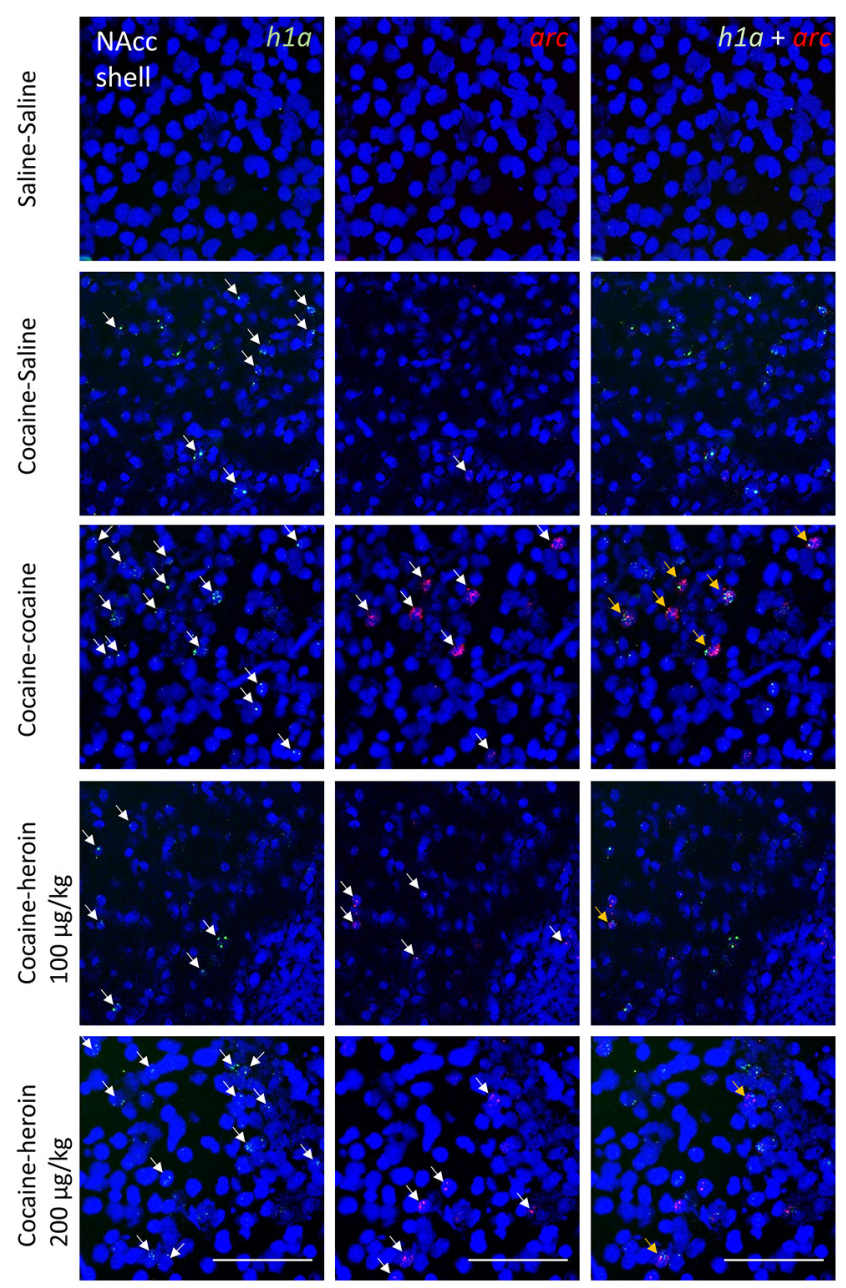

Figure 5. Representative microscope images taken from the NAcc shell. DAPI-stained cell nuclei (blue) coexpress only h1a (green), only arc (red), or both. The columns show green and red channels separately and then merged. Scale bars, $0.1 \mathrm{~mm}$. Arrows point to mRNA $^{+}$nuclei. 


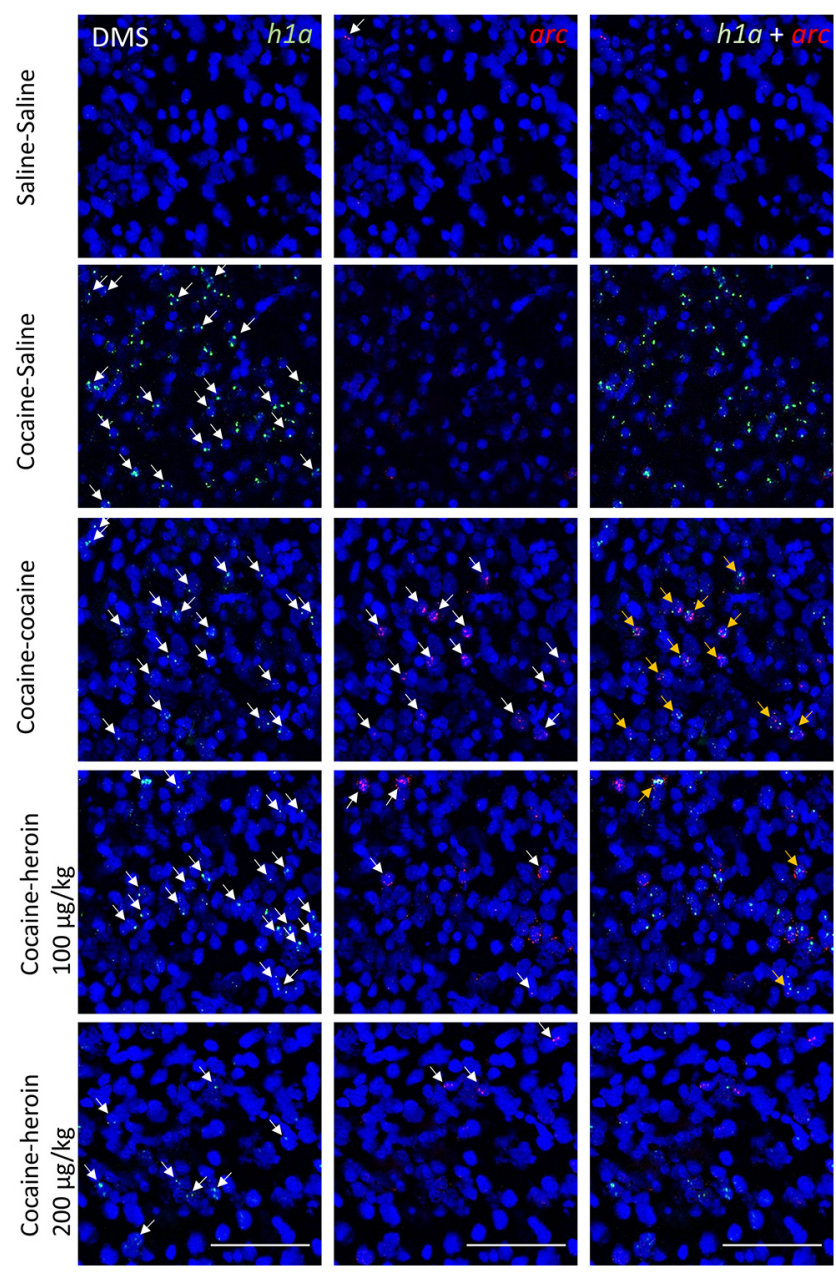

Figure 6. Representative microscope images taken from the DMS. DAPI-stained cell nuclei (blue) coexpress only h1a (green), only arc (red), or both. The columns show green and red channels separately and then merged. Scale bars, $0.1 \mathrm{~mm}$. Arrows point to $\mathrm{mRNA}^{+}$nuclei.

\section{Discussion}

We have shown that intravenous injections of heroin and cocaine at doses typically self-administered by rats produce a quick and transient increase of homer 1a and arc expression across the striatum. More importantly, using the catFISH technique, we took advantage of the difference in the timing of expression between the two IEGs to show that heroin and cocaine activate partly distinct neuronal populations in this brain area.

In line with our findings, previous studies have shown that heroin and cocaine increase c-fos levels in the ventral and dorsomedial striatum (Hope et al., 1992; Harlan and Garcia, 1998; Uslaner et al., 2001; Ferguson et al., 2004; Paolone et al., 2007; Celentano et al., 2009). The IEG c-fos is a marker of neuronal activity expressed under similar conditions of arc and homer 1a (Guzowski et al., 2001). In addition, our findings indicate that this activity occurs in separate neuronal populations and may explain why only a small proportion of neurons shows similar electrophysiological responses to heroin and cocaine (Chang et al., 1998).

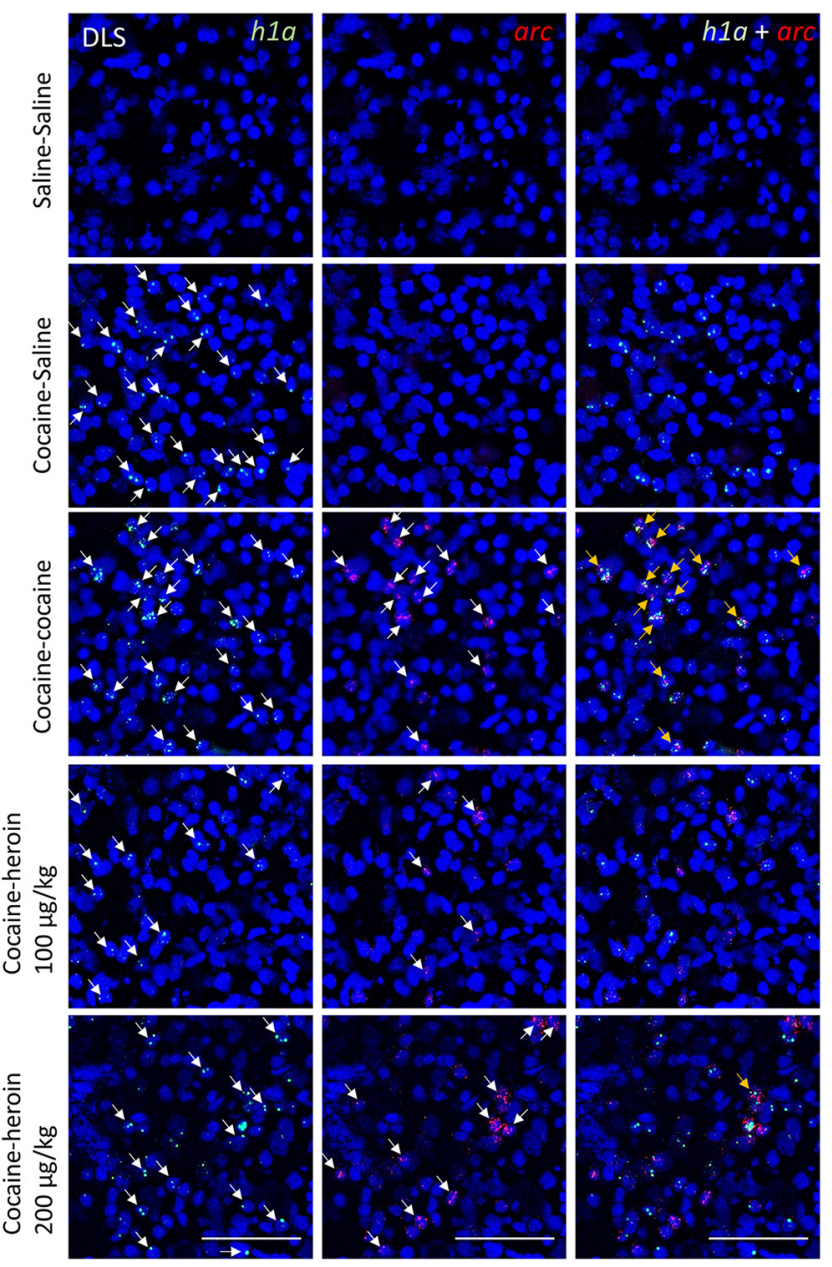

Figure 7. Representative microscope images taken from the DLS. DAPI-stained cell nuclei (blue) coexpress only h1a (green), only arc (red), or both. The columns show green and red channels separately and then merged. Scale bars, $0.1 \mathrm{~mm}$. Arrows point to $\mathrm{mRNA}^{+}$nuclei.

It is likely that drug-induced IEG expression represents glutamatergic activity modulated by DA, because NMDA and $D A D_{1}$ receptors play a key role in IEG expression through the activation of CREB (Impey et al., 1998; Mattson et al., 2005; Surmeier et al., 2007; Guez-Barber et al., 2011; Tritsch and Sabatini, 2012), and both DA and glutamate levels are increased in the striatum following heroin and cocaine administration. Note, however, that DA release alone does not produce IEG expression in the absence of glutamatergic activity (Kreuter et al., 2004). In addition, NMDA receptor activity and DA transmission in the accumbens are necessary for food and cocaine selfadministration, but not heroin self-administration (Ettenberg et al., 1982; Pettit et al., 1984; Pulvirenti et al., 1992; Kelley et al., 1997). Finally, $D_{1}$ receptor-expressing medium spiny neurons (MSNs) in the dorsal striatum appear to be sufficient to sustain operant behavior (Kravitz et al., 2012), and these neurons express IEGs (i.e., are activated) following cocaine administration. Thus, loss- and gain-offunction studies have provided evidence that the activity of cells in the striatum plays a key role for cocaine, but not 
for heroin, reinforcement through DA and glutamate transmission. The functional role of the distinct neuronal populations engaged by heroin relative to cocaine remains to be determined.

\section{A case for drug-specific neural circuitries}

Perhaps the most intriguing interpretation of the results presented here is that partly distinct neuronal populations activated by heroin and cocaine across the striatum are suggestive of dissociated circuitry processing the acute effects of the two drugs. There is already evidence that the striatum is functionally and structurally organized to accommodate circuits that operate in parallel but carry out separate functions. First, striatal MSNs are characterized by more or less excitable states (i.e., "up" and "down" states; Wolf et al., 2001; O'Donnell, 2003), and in order for MSNs to be excited (and to express IEGs), they must receive input from several sources, which may include different combinations of amygdala, hippocampus, thalamus, PFC, and VTA/SNc afferent inputs (Pennartz et al., 1994). Each of the brain areas sending these afferent projections (1) is affected differently by heroin, cocaine, and natural rewards (Chang et al., 1998; Mukherjee et al., 2018); (2) contains neuronal ensembles involved in distinct functions (Zelikowsky et al., 2014; Warren et al., 2016); and (3) might be composed of genetically distinct projection neurons. Thus, considering the integrative function of the striatum, the diverse connectivity and specialized functions of its input regions, and the necessity for synchronized excitatory input to elicit action potentials from MSNs, it is quite possible that the activation of partly distinct neuronal populations in the striatum reflects the activation of dissociated circuitries. Here it must be noted that, although the afferent inputs of the striatum from limbic and cortical areas are topographically organized in a ventromedial-dorsolateral fashion, they are not constrained to perfectly defined striatal subregions, but are overlapping, with higher concentrations of certain afferents in, for example, shell versus core (Voorn et al., 2004). It should also be considered that MSNs send collateral GABAergic projections to neighboring MSNs. This mutual inhibition between MSNs is another functional-anatomic feature predisposing the accumbens and the rest of striatum to accommodate neuronal ensembles embedded in distinct circuitries; while one ensemble is active, it can decrease the activity in other ensembles so that only one computation is taking place over others (Pennartz et al., 1994). The experiments presented here are only suggestive of distinct striatal circuitry engaged by heroin and cocaine. Future studies should address this hypothesis by expanding on our findings in three ways. First, single-cell quantitative PCR studies can further elucidate phenotypic differences between neuronal populations activated by heroin and cocaine in terms of their genetic makeup (Hrvatin et al., 2018). Second, retrograde and anterograde labeling studies in conjunction with immunohistochemistry can reveal whether these neuronal populations connect to distinct upstream and downstream targets. And third, selective loss- and gain-of-function studies can be used to test whether inactivation of neurons responding to cocaine in the dorsal striatum and accumbens core would impair heroin reinforcement. The Daun02 technique (Koya et al., 2009, 2016) would be a useful technique in this regard, as well as other techniques that manipulate neuronal ensembles such as the TetTag approach using the Fos-tTA mouse line combined with optogenetics (Reijmers and Mayford, 2009; Liu et al., 2012; Du and Koffman, 2017).

\section{Methodological considerations}

Two caveats to the experimental design used here are worthy of mention. There are known differences between the effects of noncontingent versus contingent exposure to heroin and cocaine (Galici et al., 2000; Lecca et al., 2007; Radley et al., 2015). In the present study, we administered heroin and cocaine in a noncontingent but unsignaled manner as we were interested in comparing the acute pharmacological effects of these two drugs using IEG expression as a marker of neuronal activation. Contingent administrations (e.g., self-administration) require repeated exposure to drugs over several test sessions, which has been shown to produce habituation to IEG expression (Hope et al., 1992; Unal et al., 2009). Of course, we recognize the value of studying the encoding of drug-related information in the striatum during and after periods of drug self-administration. Future studies could use in vivo imaging techniques such as the UCLA/Inscopix Miniscope to address this question directly. A second, somewhat related caveat is that our paradigm includes a multisubstance component. It is possible that circuit activity may differ following polysubstance versus single-drug use histories. However, electrophysiological evidence from rats self-administering both substances is congruent with our findings (Chang et al., 1998). Also, we administered only two injections of cocaine and/or heroin to drug-naive rats, so it is unlikely that any long-term polysubstance use effects would have influenced our observations.

\section{Conclusion}

In summary, we found a significant dissociation in the neuronal populations responding to self-administration doses of heroin versus cocaine, as indicated by arc and homer $1 \mathrm{a}$ expression. Our findings provide a proof of concept that heroin and cocaine effects on the brain must be studied as separate phenomena, adding to the evidence of major differences among the various drugs of abuse (for review, see Badiani et al., 2011). Although the functional significance of these differences remains to be fully explored, they might have implications for both research and treatment. It is remarkable, for example, that the functional or anatomic integrity of the dopaminergic system is required for the reinforcing properties of cocaine but not of heroin (Ettenberg et al., 1982; Pettit et al., 1984; Pisanu et al., 2015), that distinct projections from the PFC to the shell of the NAcc are implicated in the relapse to cocaine versus heroin seeking after abstinence (Peters et al., 2008; Bossert et al., 2012), and that basic environmental manipulations gate in opposite directions the reinforcing, affective, and neurobiological responses to heroin versus cocaine in rats and humans (Uslaner 
et al., 2001; Ferguson et al., 2004; Caprioli et al., 2007a, 2008, 2009; Paolone et al., 2007; Celentano et al., 2009; Montanari et al., 2015; Avvisati et al., 2016; De Pirro et al., 2018; De Luca et al., 2019).

\section{References}

Avvisati R, Contu L, Stendardo E, Michetti C, Montanari C, Scattoni ML, Badiani A (2016) Ultrasonic vocalization in rats selfadministering heroin and cocaine in different settings: evidence of substance-specific interactions between drug and setting. Psychopharmacology (Berl) 233:1501-1511.

Avvisati R, Bogen IL, Andersen JM, Vindenes V, Mørland J, Badiani A, Boix $F$ (2019) The active heroin metabolite 6-acetylmorphine has robust reinforcing effects as assessed by self-administration in the rat. Neuropharmacology 150:192-199.

Badiani A, Belin D, Epstein D, Calu D, Shaham Y (2011) Opiate versus psychostimulant addiction: the differences do matter. Nat Rev Neurosci 12:685-700.

Baecker V, Travo P (2006) Cell Image Analyzer - a visual scripting interface for Image $J$ and its usage at the microscopy facility Montpellier RIO Imaging. Paper presented at 1st ImageJ User \& Developer Conference, Luxemburg, Belgium, May.

Berridge KC (2012) From prediction error to incentive salience: mesolimbic computation of reward motivation. Eur J Neurosci 35: $1124-1143$.

Berridge KC, Robinson TE (2016) Liking, wanting, and the incentivesensitization theory of addiction. Am Psychol 71:670-679.

Bossert JM, Stern AL, Theberge FR, Marchant NJ, Wang HL, Morales M, Shaham Y (2012) Role of projections from ventral medial prefrontal cortex to nucleus accumbens shell in context-induced reinstatement of heroin seeking. J Neurosci 32:4982-4991.

Caffino L, Racagni G, Fumagalli F (2011) Stress and cocaine interact to modulate Arc/Arg3.1 expression in rat brain. Psychopharmacology (Berl) 218:241-248.

Caprioli D, Celentano M, Paolone G, Badiani A (2007a) Modeling the role of environment in addiction. Prog Neuropsychopharmacol Biol Psychiatry 31:1639-1653.

Caprioli D, Paolone G, Celentano M, Testa A, Nencini P, Badiani A (2007b) Environmental modulation of cocaine self-administration in the rat. Psychopharmacology 192:397-406.

Caprioli D, Celentano M, Paolone G, Lucantonio F, Bari A, Nencini P, Badiani A (2008) Opposite environmental regulation of heroin and amphetamine self-administration in the rat. Psychopharmacology 198:395-404.

Caprioli D, Celentano M, Dubla A, Lucantonio F, Nencini P, Badiani A (2009) Ambience and drug choice: cocaine- and heroin-taking as a function of environmental context in humans and rats. Biol Psychiatry 65:893-899.

Celentano M, Caprioli D, Dipasquale P, Cardillo V, Nencini P, Gaetani S, Badiani A (2009) Drug context differently regulates cocaine versus heroin self-administration and cocaine- versus heroininduced Fos mRNA expression in the rat. Psychopharmacology (Berl) 204:349-360.

Chang JY, Janak PH, Woodward DJ (1998) Comparison of mesocorticolimbic neuronal responses during cocaine and heroin selfadministration in freely moving rats. J Neurosci 18:3098-3115.

Covey DP, Roitman MF, Garris PA (2014) Illicit dopamine transients: reconciling actions of abused drugs. Trends Neurosci 37:200-210.

Crombag HS, Badiani A, Robinson TE (1996) Signalled versus unsignalled intravenous amphetamine: large differences in the acute psychomotor response and sensitization. Brain Res 722:227-231.

Dai S, Corrigall WA, Coen KM, Kalant H (1989) Heroin selfadministration by rats: influence of dose and physical dependence. Pharmacol Biochem Behav 32:1009-1015.

De Luca MT, Montanari C, Meringolo M, Contu L, Celentano M, Badiani A (2019) Heroin versus cocaine: opposite choice as a function of context but not of drug history in the rat. Psychopharmacology (Berl) 236:787-798.
De Pirro S, Galati G, Pizzamiglio L, Badiani A (2018) The affective and neural correlates of heroin versus cocaine use in addiction are influenced by environmental setting but in opposite directions. $J$ Neurosci 38:5182-5195.

Di Chiara G, Imperato A (1988) Drugs abused by humans preferentially increase synaptic dopamine concentrations in the mesolimbic system of freely moving rats. Proc Natl Acad Sci U S A 85:5274-5278.

Du JY, Koffman EE (2017) Labeling aversive memory trace in mouse using a doxycycline-inducible expression system. Bio Protoc 7:111.

Ettenberg A, Pettit HO, Bloom FE, Koob GF (1982) Heroin and cocaine intravenous self-administration in rats: mediation by separate neural systems. Psychopharmacology (Berl) 78:204-209.

Everitt BJ, Robbins TW (2005) Neural systems of reinforcement for drug addiction: from actions to habits to compulsion. Nat Neurosci 8:1481-1489.

Ferguson SM, Thomas MJ, Robinson TE (2004) Morphine-induced c-fos mRNA expression in striatofugal circuits: modulation by dose, environmental context, and drug history. Neuropsychopharmacology 29:1664-1674.

Galici R, Pechnick RN, Poland RE, France CP (2000) Comparison of noncontingent versus contingent cocaine administration on plasma corticosterone levels in rats. Eur J Pharmacol 387:59-62.

Gottås A, Boix F, Øiestad EL, Vindenes V, Mørland J (2014) Role of 6-monoacetylmorphine in the acute release of striatal dopamine induced by intravenous heroin. Int $\mathrm{J}$ Neuropsychopharmacol 17: 1357-1365.

Guez-Barber D, Fanous S, Golden SA, Schrama R, Koya E, Stern AL, Bossert JM, Harvey BK, Picciotto MR, Hope BT (2011) FACS identifies unique cocaine-induced gene regulation in selectively activated adult striatal neurons. J Neurosci 31:4251-4259.

Guzowski JF, McNaughton BL, Barnes CA, Worley PF (1999) Environment-specific expression of the immediate-early gene Arc in hippocampal neuronal ensembles. Nat Neurosci 2:1120-1124.

Guzowski JF, Setlow B, Wagner EK, McGaugh JL (2001) Experiencedependent gene expression in the rat hippocampus after spatial learning: a comparison of the immediate-early genes Arc, c-fos, and zif268. J Neurosci 21:5089-5098.

Guzowski JF, Timlin JA, Roysam B, McNaughton BL, Worley PF, Barnes CA (2005) Mapping behaviorally relevant neural circuits with immediate-early gene expression. Curr Opin Neurobiol 15: 599-606.

Gysling K, Wang RY (1983) Morphine-induced activation of A10 dopamine neurons in the rat. Brain Res 277:119-127.

Harlan RE, Garcia MM (1998) Drugs of abuse and immediate-early genes in the forebrain. Mol Neurobiol 16:221-267.

Hope B, Kosofsky B, Hyman SE, Nestler EJ (1992) Regulation of immediate early gene expression and AP-1 binding in the rat nucleus accumbens by chronic cocaine. Proc Natl Acad Sci U S A 89:5764-5768.

Hrvatin S, Hochbaum DR, Nagy MA, Cicconet M, Robertson K, Cheadle L, Zilionis R, Ratner A, Borges-Monroy R, Klein AM, Sabatini BL, Greenberg ME (2018) Single-cell analysis of experience-dependent transcriptomic states in the mouse visual cortex. Nat Neurosci 21:120-129.

Hyman SE, Malenka RC, Nestler EJ (2006) Neural mechanisms of addiction: the role of reward-related learning and memory. Annu Rev Neurosci 29:565-598.

Impey S, Obrietan K, Wong ST, Poser S, Yano S, Wayman G, Deloulme JC, Chan G, Storm DR (1998) Cross talk between ERK and PKA is required for $\mathrm{Ca} 2+$ stimulation of CREB-dependent transcription and ERK nuclear translocation. Neuron 21:869-883.

Jentsch JD, Taylor JR (1999) Impulsivity resulting from frontostriatal dysfunction in drug abuse: implications for the control of behavior by reward-related stimuli. Psychopharmacology (Berl) 146:373390.

Johanson CE, Fischman MW (1989) The pharmacology of cocaine related to its abuse. Pharmacol Rev 41:3-52. 
Johnson SW, North RA (1992) Opioids excite dopamine neurons by hyperpolarization of local interneurons. J Neurosci 12:483-488.

Kawashima T, Okuno H, Bito H (2014) A new era for functional labeling of neurons: activity-dependent promoters have come of age. Front Neural Circuit 8:37.

Keiflin R, Janak PH (2015) Dopamine prediction errors in reward learning and addiction: from theory to neural circuitry. Neuron 88:247-263.

Kelley AE, Smith-Roe SL, Holahan MR (1997) Responsereinforcement learning is dependent on $\mathrm{N}$-methyl-D-aspartate receptor activation in the nucleus accumbens core. Proc Natl Acad Sci U S A 94:12174-12179.

Keramati M, Ahmed SH, Gutkin BS (2017) Misdeed of the need: towards computational accounts of transition to addiction. Curr Opin Neurobiol 46:142-153.

Koob GF, Volkow ND (2010) Neurocircuitry of addiction. Neuropsychopharmacology 35:217-238.

Koya E, Golden SA, Harvey BK, Guez-Barber DH, Berkow A, Simmons DE, Bossert JM, Nair SG, Uejima JL, Marin MT, Mitchell TB, Farquhar D, Ghosh SC, Mattson BJ, Hope BT (2009) Targeted disruption of cocaine-activated nucleus accumbens neurons prevents context-specific sensitization. Nat Neurosci 12:1069-1073.

Koya E, Margetts-Smith G, Hope BT (2016) Daun02 inactivation of behaviorally activated Fos-expressing neuronal ensembles. Curr Protoc Neurosci 76:8.36.31-38.36.17.

Kravitz AV, Tye LD, Kreitzer AC (2012) Distinct roles for direct and indirect pathway striatal neurons in reinforcement. Nat Neurosci 15:816-818.

Kreuter JD, Mattson BJ, Wang B, You ZB, Hope BT (2004) Cocaineinduced Fos expression in rat striatum is blocked by chloral hydrate or urethane. Neuroscience 127:233-242.

Kuczenski R, Segal DS, Weinberger SB, Browne RG (1982) Evidence that a behavioral augmentation following repeated amphetamine administration does not involve peripheral mechanisms. Pharmacol Biochem Behav 17:547-553.

Lecca D, Valentini V, Cacciapaglia F, Acquas E, Di Chiara G (2007) Reciprocal effects of response contingent and noncontingent intravenous heroin on in vivo nucleus accumbens shell versus core dopamine in the rat: a repeated sampling microdialysis study. Psychopharmacology (Berl) 194:103-116.

Liu X, Ramirez S, Pang PT, Puryear CB, Govindarajan A, Deisseroth $\mathrm{K}$, Tonegawa S (2012) Optogenetic stimulation of a hippocampal engram activates fear memory recall. Nature 484:381-U415.

Mandt BH, Johnston NL, Zahniser NR, Allen RM (2012) Acquisition of cocaine self-administration in male Sprague-Dawley rats: effects of cocaine dose but not initial locomotor response to cocaine. Psychopharmacology (Berl) 219:1089-1097.

Mantsch JR, Ho A, Schlussman SD, Kreek MJ (2001) Predictable individual differences in the initiation of cocaine self-administration by rats under extended-access conditions are dose-dependent. Psychopharmacology (Berl) 157:31-39.

Matthews RT, German DC (1984) Electrophysiological evidence for excitation of rat ventral tegmental area dopamine neurons by morphine. Neuroscience 11:617-625.

Mattson BJ, Bossert JM, Simmons DE, Nozaki N, Nagarkar D, Kreuter JD, Hope BT (2005) Cocaine-induced CREB phosphorylation in nucleus accumbens of cocaine-sensitized rats is enabled by enhanced activation of extracellular signal-related kinase, but not protein kinase A. J Neurochem 95:1481-1494.

Montanari C, Stendardo E, De Luca MT, Meringolo M, Contu L, Badiani A (2015) Differential vulnerability to relapse into heroin versus cocaine-seeking as a function of setting. Psychopharmacology (Berl) 232:2415-2424.

Mukherjee D, Ignatowska-Jankowska BM, Itskovits E, Gonzales BJ, Turm H, Izakson L, Haritan D, Bleistein N, Cohen C, Amit I, Shay T, Grueter B, Zaslaver A, Citri A (2018) Salient experiences are represented by unique transcriptional signatures in the mouse brain. Elife 7:e31220.

Nestler EJ (2001) Molecular basis of long-term plasticity underlying addiction. Nat Rev Neurosci 2:119-128.
Nestler EJ (2004) Historical review: molecular and cellular mechanisms of opiate and cocaine addiction. Trends Pharmacol Sci 25:210-218.

O'Donnell P (2003) Dopamine gating of forebrain neural ensembles. Eur J Neurosci 17:429-435.

Paolone G, Conversi D, Caprioli D, Bianco PD, Nencini P, Cabib S, Badiani A (2007) Modulatory effect of environmental context and drug history on heroin-induced psychomotor activity and fos protein expression in the rat brain. Neuropsychopharmacology 32: 2611-2623.

Paxinos G, Watson C (1986) The rat brain in stereotaxic coordinates, Ed 2. London: Academic.

Pennartz CM, Groenewegen HJ, Lopes da Silva FH (1994) The nucleus accumbens as a complex of functionally distinct neuronal ensembles: an integration of behavioural, electrophysiological and anatomical data. Prog Neurobiol 42:719-761.

Peters J, LaLumiere RT, Kalivas PW (2008) Infralimbic prefrontal cortex is responsible for inhibiting cocaine seeking in extinguished rats. J Neurosci 28:6046-6053.

Pettit HO, Justice JB Jr (1991) Effect of dose on cocaine selfadministration behavior and dopamine levels in the nucleus accumbens. Brain Res 539:94-102.

Pettit HO, Ettenberg A, Bloom FE, Koob GF (1984) Destruction of dopamine in the nucleus accumbens selectively attenuates cocaine but not heroin self-administration in rats. Psychopharmacology (Berl) 84:167-173.

Pisanu A, Lecca D, Valentini V, Bahi A, Dreyer JL, Cacciapaglia F, Scifo A, Piras G, Cadoni C, Di Chiara G (2015) Impairment of acquisition of intravenous cocaine self-administration by RNAinterference of dopamine D1-receptors in the nucleus accumbens shell. Neuropharmacology 89:398-411.

Pulvirenti L, Maldonado-Lopez R, Koob GF (1992) NMDA receptors in the nucleus accumbens modulate intravenous cocaine but not heroin self-administration in the rat. Brain Res 594:327-330.

Radley JJ, Anderson RM, Cosme CV, Glanz RM, Miller MC, RomigMartin SA, LaLumiere RT (2015) The contingency of cocaine administration accounts for structural and functional medial prefrontal deficits and increased adrenocortical activation. J Neurosci 35:11897-11910.

Reijmers L, Mayford M (2009) Genetic control of active neural circuits. Front Mol Neurosci 2:27.

Roberts DC, Loh EA, Vickers G (1989) Self-administration of cocaine on a progressive ratio schedule in rats: dose-response relationship and effect of haloperidol pretreatment. Psychopharmacology (Berl) 97:535-538.

Robinson TE, Berridge KC (1993) The neural basis of drug craving: an incentive-sensitization theory of addiction. Brain Res Brain Res Rev 18:247-291.

Sato M, Suzuki K, Nakanishi S (2001) NMDA receptor stimulation and brain-derived neurotrophic factor upregulate homer 1a mRNA via the mitogen-activated protein kinase cascade in cultured cerebellar granule cells. J Neurosci 21:3797-3805.

Shaham Y, Stewart J (1994) Exposure to mild stress enhances the reinforcing efficacy of intravenous heroin self-administration in rats. Psychopharmacology (Berl) 114:523-527.

Surmeier DJ, Ding J, Day M, Wang Z, Shen W (2007) D1 and D2 dopamine-receptor modulation of striatal glutamatergic signaling in striatal medium spiny neurons. Trends Neurosci 30:228-235.

Tritsch NX, Sabatini BL (2012) Dopaminergic modulation of synaptic transmission in cortex and striatum. Neuron 76:33-50.

Unal CT, Beverley JA, Willuhn I, Steiner H (2009) Long-lasting dysregulation of gene expression in corticostriatal circuits after repeated cocaine treatment in adult rats: effects on zif 268 and homer 1a. Eur J Neurosci 29:1615-1626.

Uslaner J, Badiani A, Day HE, Watson SJ, Akil H, Robinson TE (2001) Environmental context modulates the ability of cocaine and amphetamine to induce c-fos mRNA expression in the neocortex, caudate nucleus, and nucleus accumbens. Brain Res 920:106116. 
Vander Weele CM, Porter-Stransky KA, Mabrouk OS, Lovic V, Singer BF, Kennedy RT, Aragona BJ (2014) Rapid dopamine transmission within the nucleus accumbens: dramatic difference between morphine and oxycodone delivery. Eur J Neurosci 40:3041-3054.

Vazdarjanova A, Guzowski JF (2004) Differences in hippocampal neuronal population responses to modifications of an environmental context: evidence for distinct, yet complementary, functions of CA3 and CA1 ensembles. J Neurosci 24:6489-6496.

Vazdarjanova A, McNaughton BL, Barnes CA, Worley PF, Guzowski JF (2002) Experience-dependent coincident expression of the effector immediate-early genes arc and Homer 1a in hippocampal and neocortical neuronal networks. J Neurosci 22:10067-10071.

Volkow ND, Morales M (2015) the brain on drugs: from reward to addiction. Cell 162:712-725.

Volkow ND, Wise RA, Baler R (2017) The dopamine motive system: implications for drug and food addiction. Nat Rev Neurosci 18: 741-752.

Voorn P, Vanderschuren LJ, Groenewegen HJ, Robbins TW, Pennartz CM (2004) Putting a spin on the dorsal-ventral divide of the striatum. Trends Neurosci 27:468-474.

Warren BL, Mendoza MP, Cruz FC, Leao RM, Caprioli D, Rubio FJ, Whitaker LR, McPherson KB, Bossert JM, Shaham Y, Hope BT (2016) Distinct Fos-expressing neuronal ensembles in the ventromedial prefrontal cortex mediate food reward and extinction memories. J Neurosci 36:6691-6703.
Wee S, Specio SE, Koob GF (2007) Effects of dose and session duration on cocaine self-administration in rats. J Pharmacol Exp Ther 320:1134-1143.

Wei C, Han X, Weng D, Feng Q, Qi X, Li J, Luo M (2018) Response dynamics of midbrain dopamine neurons and serotonin neurons to heroin, nicotine, cocaine, and MDMA. Cell Discov 4:60.

Wise RA (1996) Neurobiology of addiction. Curr Opin Neurobiol 6:243-251.

Wise RA, Leone P, Rivest R, Leeb K (1995) Elevations of nucleus accumbens dopamine and DOPAC levels during intravenous heroin self-administration. Synapse 21:140-148.

Wolf JA, Schroeder LF, Finkel LH (2001) Computational modeling of medium spiny projection neurons in nucleus accumbens: toward the cellular mechanisms of afferent stream integration. Proceedings of the IEEE 89:1083-1092.

Wolf ME (2010) The Bermuda triangle of cocaine-induced neuroadaptations. Trends Neurosci 33:391-398.

Zelikowsky M, Hersman S, Chawla MK, Barnes CA, Fanselow MS (2014) Neuronal ensembles in amygdala, hippocampus, and prefrontal cortex track differential components of contextual fear. $J$ Neurosci 34:8462-8466.

Zito KA, Vickers G, Roberts DC (1985) Disruption of cocaine and heroin self-administration following kainic acid lesions of the nucleus accumbens. Pharmacol Biochem Behav 23:1029-1036. 